\title{
Sosyo
}

Ekonomi

\section{Çok Özellikli Ürünlerin Testinde Makine Seçim Optimizasyonu İçin Kısıt Programlama Uygulaması}

\author{
Onur KOYUNCU \\ okoyuncu@ hacettepe.edu.tr
}

\section{Optimization of Equipment Selection for Testing Multiple Attribute Products Using Constraint Programming}

\begin{abstract}
Testing process is an important cost component, especially for complex products, where companies must carefully plan their resources. Also, the testing of multiple attribute products has a direct effect on yield quality and related costs. Current research does not consider the test and repair equipment selection problem as an optimization problem. This paper briefly describes a test process based on an imperfect test-repair loop and describes a constraint programming approach as a solution method. Model stands for an economic choice of test selection equipment with a realistic cost estimation approach which can also be generalized for repair equipment's.
\end{abstract}

Keywords

: Test Design, Equipment Selection, Optimization, Constraint Programming.

JEL Classification Codes : A12, C61, L15.

\section{Özet}

Test süreci, özellikle karmaşık ürünler için, işletme kaynaklarının doğru planlanmasını gerektiren önemli bir maliyet kapısıdır. Çok özellikli ürünlerin testleri ise çıktı kalitesini ve ilintili maliyetleri doğrudan etkilemektedir. Literatürde test ve tamir makinesi seçimi, bir optimizasyon problemi olarak ele alınmamaktadır. Bu çalışmada mükemmel olmayan bir test ve tamir döngüsü altında çok özellikli ürünlerin testi için makine seçim optimizasyonu problemini çözecek bir kısıt programlama modelinin yapısı açıklanmaktadır. Tamir makineleri için de genellenebilecek bu model, gerçekçi bir maliyet hesabı yaklaşımıyla ideal test makinesi seçimi yapılmasına yardım etmektedir. 
Onur KOYUNCU

212 


\section{Giriş}

Karmaşık ürünlerin test süreçleri, hem mühendislik hem de yönetim bilimleri açısından ele alındığında modellenmesi ve çözümü zor problemler ortaya koymaktadır. Özellikle elektronik ürünlerin (özellikli olarak telekomünikasyon sektöründe kullanılan elektronik kart ve devrelerin) test süreçleri, bu araştırma alanının sıklıkla incelenen bir alt kümesidir. Yaklaşık yarım asırdır mühendislerce teknik açıdan incelenen bu probleme, yönetim bilimi araştırmacıları da son 30 senedir dâhil olmuştur. Bunun temel nedeni, problemin kaçınılmaz bir açılım olarak maliyet içerikli çalışmalara yol açması ve hızla yaygınlaşan bu bakış açısının giderek daha çok yönetim bilimleri alanınca kapsanır hale gelmesidir.

Test maliyetleri, genel maliyet tanımıyla uyumlu olarak sabit ve değişken maliyetler olarak ikiye ayrılır. Sabit maliyetlerin temel öğesi makine yatırımıdır. Makine maliyetini etkileyen birçok faktör vardır. Makinelerin seçim süreci, sektör, firma büyüklüğü, üretim kapasitesi ve test içeriğine bağlı olarak değişebilmekte olup, maliyetleri birkaç bin dolardan yüz binlerce dolara kadar değişebilecek tasarruf imkânı sunabilir. Makinelerin yanı sıra test cihazları için geliştirilen yazılımlar da sabit maliyet sınıfına girebilecek olup, son derece önemli ve yüksek bir maliyet kalemi olarak değer kazanmaktadır. Değişken maliyetler ise üretimin tüm süreçleri boyunca bazen faaliyete bağlı, bazen de faaliyetten bağımsız olarak oluşan maliyetlerdir. Bu maliyet tipi de kendi içinde farklı gruplara ayrılmaktadır. Bunların arasında işgücü, test ve tamir işlemlerinin aldığı süre, test ve tamir makinelerinin performansları ve kapasitelerinden kaynaklanacak maliyetler ve çıtılardan (özellikle hatalı çıtılardan) kaynaklanan geri dönüş maliyetleri ve diğer sarf maliyetleri bulunmaktadır.

Test ve tamir makinelerinin verimlilik ve isabetli sonuç verebilme oranlarından kaynaklanan maliyetler bu çalışmada performans maliyetleri olarak tanımlanmıştır. Test ve tamir makinelerinin hatalı çalışmaları durumunda performans maliyetleri oluşmaktadır. Örneğin bir ürün testi geçemeyip tamir makinesine aktarıldığı zaman, üzerinde bulunan hata gerçekte düzeltilememişse, aynı testten tekrar başarısız olacağı beklenebilir. Böyle bir durumda da ürün test sisteminde fazladan bir turu firmaya hiçbir katma değer sağlamadan atmış ve maliyetleri artırmış olacaktır. Bu durum tamir makinesi performansının yol açacağı maliyetlere bir örnektir.

Test makinesi performansında görülecek olası hatalar ise firmanın son kullanım için sevk edeceği nihai ürünlerdeki hata oranlarını etkileyecektir. Test makinesinin hatasız kabul ettiği fakat gerçekte hatalı olan bir ürün, en kötü ihtimalle son kullanılacağı yerde fark edilecektir. Böylesi durumlarda ürünün değiştirilmesi, yerinde tamiri, firmaya geri 
yollanarak firmada tamiri, lojistik ve ulaşım masrafları, firmanın piyasadaki imajının zarar görmesi nedeniyle oluşabilecek satış kayıpları gibi maliyetler oluşacaktır.

Çalışmanın ikinci bölümünde problem tanımı ve ilgili literatür verilecek, üçüncü kısımda tek ürün için test optimizasyon problemi tanımlanacak, dördüncü kısımda çok özellikli testin temel kavramları açıklanacak ve beşinci kısımda çok özellikli bağımsız test optimizasyonu için bir kısıt programlama modeli geliştirilecektir.

\section{Problem Tanımı ve Literatür}

Test sürecine dair ilk çalışmalar testlerde hata saptanması ve ilintili olasılık dağılımlarını inceleyen Gluss (1959) ve tamir edilebilirlik ve test planlaması konularına odaklanan Flehinger'in (1965) çalışmalarıdır. Maliyet temelli çalışmaların ilk önemli örneğinde ise Dislis, Dear, Miles, Rau ve Ambler (1988), farklı test stratejilerini maliyet açısından karşılaştırmakta ve test makinesi ihtiyacını saptamaya yönelik bir çerçeve sunmaya çalışmaktadırlar. Gerçekçi maliyet modellemeleri oluşturan Nachlas, Loney ve Binney (1990), test sürecinin ana maliyetlerini test ve tamir süreçlerinden kaynaklanan ve hatalı test sonucu müşteriye sevk edilen hatalı ürünlerin maliyetlerinin toplamı olarak ele almışlardır. Dick, Trischler, Dislis ve Ambler (1994), test maliyet hesabında potansiyel olarak incelenebilecek çok sayıda değişkenin her birinin aynı öneme sahip olmadığını savunmuş ve geliştirdikleri duyarlılık analizi yaklaşımlarıyla, üretim hacmi, üretim maliyeti, hata kapsanması gibi faktörleri içeren beş parametreyi incelemenin yeterli olacağını göstermişlerdir. Volkerink, Khoche, Kamas, Rivoir ve Kerkhoff (2001), test için hangi mali kaynakların ne şekilde kullanılması gerektiği bilgisinin endüstri tarafindan hala net olarak bilinmediğini belirtmektedir.

Yakın tarihli çalışmalarda, test maliyetlerini açıklamak amacıyla test döngüleri ortaya konmuş ve ayrıntılı hesaplamalar yapılmıştır. Örneğin Goyal ve Mosher (2006), basit bir test döngüsü üzerinden test süresi ve çıktı oranlarına bağlı maliyet hesapları yapmıştır. Rossi, Tarım, Hnich ve Prestwich (2006), yine benzer döngülerle çok özellikli ve etkileşimli (bir test ya da tamir işleminin farklı özellikleri de etkilemesi) karmaşık test süreçlerinde ürün bileşenlerindeki hata olasılıklarını hesaplayan bir model geliştirmişlerdir. Fisher ve ark. (2007a ve 2007b), aynı döngülerle test maliyeti için kesin hesap yöntemleri oluşturmuş ve sistemi kontrol edecek bir yazılım önermiştir. Wilson ve ark. (2007) ve Wilson ve Goyal (2012), yine aynı yapıdaki test döngüleri için hata olasılığı tahmini yöntemlerine odaklanmışlardır. Yine de bu çalışmaların hiç birinde makine seçimi ve optimizasyonu problemine çözüm getirilmemiştir. 


\section{Tek Özellikli Test için Makine Optimizasyonu}

$\mathrm{Bu}$ kısımda çok özellikli test makinesi optimizasyonu problemine altyap1 oluşturacak tek özellikli ürüne dair geliştirilen model tanımlanacaktır. Yaygın olarak kullanılan tek ürün test döngüsü Şekil: 1'de verilmiştir.

Şekil: 1

\section{Temel Test Akışı Karar Değişkenleri}

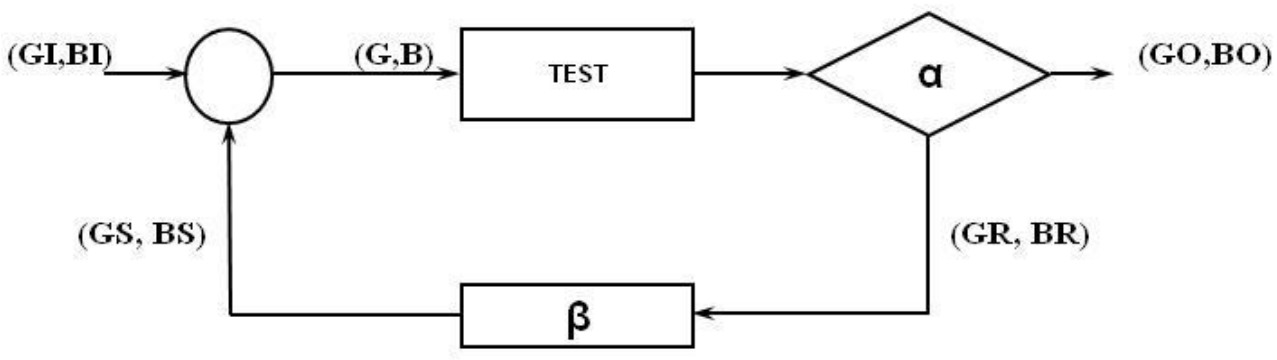

Test tasarımı ve hesaplamalarında kullanılan temel kavramların kolayca açıklanabilmesi için bu çalışmalarda da görülen olası en basit test akışı örnek olarak kullanılacaktır. Test makineleri $\alpha$ olasılıklarıyla gelen ürünleri test etmekte (TP, true passsağlam ürünün testi geçmesi, TF, true fail- bozuk ürünün testi geçememesi, FP, false passbozuk ürünün testi geçmesi, FF, false fail- sağlam ürünün testi geçememesi), tamir makineleri ise $\beta$ olasılıklarıyla (GG, good to good- sağlam ürünün tamirden sağlam çıkması, GB, good to bad- sağlam ürünün tamirden bozuk çıkması, BB, bad to bad-bozuk ürünün tamirden bozuk çıkması, BG, bad to good- bozuk ürünün tamirden sağlam çıkması) tamir işlemi yapmaktadır.

A ̆ yapısına sahip bu test döngüsünde, test ve tamir makinelerinin performans olasılıkları arasında şu eşitliklerin geçerli olduğu gözlenecektir:

$$
\begin{aligned}
& \alpha_{\mathrm{TP}}+\alpha_{\mathrm{FF}}=1 \\
& \alpha_{\mathrm{FP}}+\alpha_{\mathrm{TF}}=1 \\
& \beta_{\mathrm{GG}}+\beta_{\mathrm{GB}}=1 \\
& \beta_{\mathrm{BG}}+\beta_{\mathrm{BB}}=1
\end{aligned}
$$


Bu durumda Şekil: 1'de gösterilen ağ modelinin matematiksel ifadesi şöyle olacaktır:

$$
\begin{array}{ll}
G O=\alpha_{T P} * G & \text { Sağlam ürünlerden testi geçenler } \\
B O=\alpha_{F P} * B & \text { Bozuk ürünlerden testi geçenler } \\
G R=\alpha_{F F} * G & \text { Sağlam olduğu halde tamire ayrılanlar } \\
B R=\alpha_{T F} * B & \text { Bozuk olup teste gidenler } \\
G S=\beta_{B G} * B R+\beta_{G G} * G R & \text { Tamirden çıkan sağlam ürünler } \\
B S=\beta_{B B} * B R+\beta_{G B} * G R & \text { Tamirden çıkan bozuk ürünler } \\
G=G S+G I & \text { Teste giren toplam sağlam ürünler } \\
B=B S+B I & \text { Teste giren toplam bozuk ürünler }
\end{array}
$$

Modelde GI ve BI değişkenleri sırasıyla test sistemine girdi oluşturan hatasız ve hatalı ürün sayılarını, $\mathrm{G}$ ve $\mathrm{B}$ değişkenleri teste giren toplam hatasız ve hatalı ürünleri, GO ve $\mathrm{BO}$ değişkenleri test makinesinden sevk onayı alan hatasız ve hatalı ürünleri göstermektedir. GR ve BR değişkenleri testten başarısız olarak tamir makinesine aktarılan hatasız ve hatalı ürünleri, GS ve BS ise tamir gördükten sonra tekrar test makinesine gönderilen hatasız ve hatalı ürünleri göstermektedir. Bu ifadeler aynı zamanda test akışı parametrelerini hesaplamakta kullanılacak matematiksel bir modelin, bir doğrusal denklemler kümesinin bileşenleri olarak da kullanılmaktadır. Test tekrarını da içerecek dinamik bir yapı elde etmek için, denklem setine, tekrar edilecek test sayısını gösterecek şekilde, $\mathrm{t}$ indeksi eklenebilir.

Böyle bir döngünün test makinesi seçimi için iki test makinesi ve bir tamir makinesi içeren optimizasyon modeli aşağıda görülmektedir. Modelde, yukarıda açıklanan değişkenler dışında $\mathrm{GT}_{\mathrm{i}}$ ve $\mathrm{BT}_{\mathrm{i}}$ karar değişkenleri (i test makinesine gönderilen hatasız ve hatalı ürünler) ve $t$ testinde kullanılan $t_{i}$ tipi makine sayısını gösteren use $\left[t_{i}, t\right]$ karar değişkeni kullanılmıştır. Diğer parametrelerin (maliyet, kapasite, vb. sabitler) açıklamaları modelin altında açıklanmaktadır. 
Minimize

$\mathrm{VcR} *(\mathrm{GS}[1]+\mathrm{BS}[1])+\mathrm{Fc} * \mathrm{BO}[1]+\sum_{\mathrm{i}=1}^{2} \mathrm{VcT}_{\mathrm{i}} *\left(\mathrm{GT}_{\mathrm{i}}[1]+\mathrm{BT}_{\mathrm{i}}[1]\right)+\sum_{\mathrm{i}=1}^{2} \mathrm{FcT}_{\mathrm{i}} *$ use[t $\left.\mathrm{t}_{\mathrm{i}}, 1\right]$

Kisitlar:

$\mathrm{GI}[0]=50$

$\mathrm{BI}[0]=50$

$\mathrm{GO}[\mathrm{t}]=\alpha_{\mathrm{TP}, \mathrm{T} 1}[\mathrm{t}] * \mathrm{GT}_{1}[\mathrm{t}]+\alpha_{\mathrm{TP}, \mathrm{T} 2}[\mathrm{t}] * \mathrm{GT}_{2}[\mathrm{t}]$

$\mathrm{GS}[\mathrm{t}]+\mathrm{GI}[\mathrm{t}-1]=\mathrm{GT}_{1}[\mathrm{t}]+\mathrm{GT}_{2}[\mathrm{t}]$

$\mathrm{GR}[\mathrm{t}]=\alpha_{\mathrm{FF}, \mathrm{T} 1}[\mathrm{t}] * \mathrm{GT}_{1}[\mathrm{t}]+\alpha_{\mathrm{FF}, \mathrm{T} 2}[\mathrm{t}] * \mathrm{GT}_{2}[\mathrm{t}]$

$\mathrm{GS}[\mathrm{t}]=\beta_{\mathrm{GG}} * \mathrm{GR}[\mathrm{t}]+\beta_{\mathrm{BG}} * \mathrm{BR}[\mathrm{t}]$

$\mathrm{BO}[\mathrm{t}]=\alpha_{\mathrm{pp}, \mathrm{T} 1}[\mathrm{t}] * \mathrm{BT}_{1}[\mathrm{t}]+\alpha_{\mathrm{pP}, \mathrm{T} 2}[\mathrm{t}] * \mathrm{BT}_{2}[\mathrm{t}]$

$\mathrm{BS}[\mathrm{t}]+\mathrm{BI}[\mathrm{t}-1]=\mathrm{BT}_{1}[\mathrm{t}]+\mathrm{BT}_{2}[\mathrm{t}]$

$\mathrm{BR}[\mathrm{t}]=\alpha_{\mathrm{TF}, \mathrm{T} 1}[\mathrm{t}] * \mathrm{BT}_{1}[\mathrm{t}]+\alpha_{\mathrm{TF}, \mathrm{T} 2}[\mathrm{t}] * \mathrm{BT}_{2}[\mathrm{t}]$

$\mathrm{BS}[\mathrm{t}]=\beta_{\mathrm{GB}} * \mathrm{GR}[\mathrm{t}]+\beta_{\mathrm{BB}} * \mathrm{BR}[\mathrm{t}]$

$\mathrm{GI}[\mathrm{t}]+\mathrm{BI}[\mathrm{t}]=\mathrm{GI}[\mathrm{t}-1]+\mathrm{BI}[\mathrm{t}-1]$

$\mathrm{GT}_{\mathrm{i}}[\mathrm{t}]+\mathrm{BT}_{\mathrm{i}}[\mathrm{t}] \leq \operatorname{cap}_{\mathrm{Ti}} * \mathrm{use}\left[\mathrm{T}_{\mathrm{i}}, \mathrm{t}\right], \forall i \in(1,2)$

$\sum_{i} u s e[i, t] \leq n m$ 


$$
\begin{aligned}
& \operatorname{use}\left[\mathrm{T}_{\mathrm{i}}, \mathrm{t}\right]>0 \Rightarrow 100 * \frac{(\mathrm{GI}[\mathrm{t}-1]-3)}{(\mathrm{GI}[\mathrm{t}-1]+\mathrm{BI}[\mathrm{t}-1])} \leq 100 * \frac{\mathrm{GT}_{\mathrm{i}}[\mathrm{t}]}{\left(\mathrm{GT}_{\mathrm{i}}[\mathrm{t}]+\mathrm{BT}_{\mathrm{i}}[\mathrm{t}]\right)} \leq 100 * \frac{(\mathrm{GI}[\mathrm{t}-1]+3)}{(\mathrm{GI}[\mathrm{t}-1]+\mathrm{BI}[\mathrm{t}-1])} \\
& \forall i \in(1,2)
\end{aligned}
$$

Amaç fonksiyonu (13), tamir makinesinin değişken tamir maliyetleri ( $\mathrm{VcR})$ ve testi geçen hatalı ürünlerin maliyetleri $(\mathrm{Fc})$ ile $\mathrm{T} 1$ ve $\mathrm{T} 2$ test makinelerinin toplam değişken test maliyetleri (VcT), ve makine maliyetleri ( $\mathrm{FcT}$ ) toplamını minimize eder. İlk iki kısıt (14-15), sıfır indeksi ile girdiler içindeki hatasız ve hatalı ürün sayılarını gösterir. Takip eden kısıt setleri, sırasıyla hatasız (G) ve hatalı (B) ürünlerin akışlarını gösterir. Girdiler (GI-BI), iki test makinesine dağılacak (16 ve 20), girdi ve tamir edilenlerin toplamı, test edilenlerin toplamına eşit olacak (17 ve 21$)$, testten geçemeyenler tamire gidecek (18 ve 22 ) ve tamire giren ürünler işlem görecektir (19 ve 23). (24), girdi ve çıktıların sayısını eşitlemektedir. (25), test makinelerinin kapasitelerini sınırlandırmakta ve mevcut kapasitelerine dayanarak kaç adet test makinesi kullanılması gerektiğini saptamaktadır. Kullanılacak test makinesi sayısı "use" değişkeni ile gösterilmektedir. (26) toplam kullanılan makine sayısı için bir üst sınır (en çok nm adet) oluşturmaktadır. (27) ise testten çıkan ürünlerin içindeki hatasız ürün oranını belirli bir oranın üzerinde tutmak üzere yazılmıştır. Burada karşılaşılan y değişkeni, istenen çıktı oranını göstermektedir. (28) (tam sayılaştırılmış kısıt) ise çözümde bulunan her test makinesine, birbirine yakın oranda hatasız malzeme göndermek amaçlıdır. Bu kısıt kullanılmadığı takdirde her türlü optimizasyon çözüm programı, bilgiyi istismar ederek hatasız ürünleri TP olasıllğı yüksek makinelerde, hatalı ürünleri ise TF olasılığı yüksek makinelerde test etmeye çalışmaktadır. $\mathrm{Bu}$ kısıt ayrıca kısıt programlama kullanımını zorunlu hale getiren kısıttır. Kısıt eğer bir makine kullanılıyorsa, bu makineye test girdi popülasyonunda karşlaşılan oranlara yakın oranlarda hatalı ve hatasız ürün beslenmesini söylediği için hem mantık gerektirmesi nedeniyle hem de oranlar içermesi nedeniyle doğrusal olmayan bir yapı oluşturur. Böylesi bir yapı da ancak tam sayı ile gösterilen değişkenler kullanılarak kısıt programlama ile çözülebilir. Doğal bir sonuç olarak girdi popülasyonundaki hatasız ve hatalı ürün oranları adet cinsine çevrilir ve tüm modelde sürekli değişkenler yerine tam sayılı değişkenler kullanılır.

Örnek bir problemde test makinesi seçim optimizasyonu kısıt programlama ile çözülmüş ve cebirsel çözüm ile karşılaştırmalı sonuçları Tablo 1'de verilmiştir. Bu problemde girdi kitle dağılımı [50,50] olarak saptanmıs, birinci makinenin TP ve TF olasılıkları sırasıyla 0.85 ve 0.95 , ikinci makinenin TP ve TF olasılıkları 0.90 kabul edilmiş ve $\varepsilon=3$ (makinelere gidecek hatasız ürünler için hata payı) olarak kullanılmıştır. Cebirsel çözüm kesin hesabı, kısıt programlama çözümü ise tam sayı yuvarlama hataları içeren 
optimal çözümü vermektedir. Her iki çözümde de ilk makineden 3, ikinci makineden 1 adet seçilmiş ve çıktı oranları yaklaşık \%97 olarak bulunmuştur. $\mathrm{Bu}$ tablo kısıt programlamanın tamsayı olarak tanımlı değişkenlerle çalıştığını ve uygulanabilir olmayan kesin hesaplarla arasında bu nedenden oluşan hata paylarını göstermektedir.

Tablo: 1

Kısıt Programlama Çözümü-Cebirsel Çözüm Karşılaştırmalı Sonuçlar

\begin{tabular}{|c|c|}
\hline KP & Cebirsel Çözüm \\
\hline $\mathrm{Z}=427000,0000$ & \\
\hline use $\left[\mathrm{T}_{1}, 1\right]=3$ & use $\left[\mathrm{T}_{1}, 1\right]=3$ \\
use[T 2,1$]=1$ & use $\left[\mathrm{T}_{2}, 1\right]=1$ \\
\hline $\mathrm{GI}[0]=50$ & $\mathrm{GI}[0]=50$ \\
$\mathrm{BI}[0]=50$ & $\mathrm{BI}[0]=50$ \\
\hline $\mathrm{GO}[1]=97$ & $\mathrm{GO}[1]=96,3$ \\
$\mathrm{BO}[1]=3$ & $\mathrm{BO}[1]=3,7$ \\
\hline $\mathrm{GT}_{1}[1]=94$ & $\mathrm{GT}_{1}[1]=83,9$ \\
$\mathrm{BT}_{1}[1]=54$ & $\mathrm{BT}_{1}[1]=42,7$ \\
\hline $\mathrm{GT}_{2}[1]=19$ & $\mathrm{GT}_{2}[1]=27,5$ \\
$\mathrm{BT}_{2}[1]=3$ & $\mathrm{BT}_{2}[1]=14,6$ \\
\hline $\mathrm{GR}[1]=16,0000$ & $\mathrm{GR}_{1}[1]=15,1$ \\
$\mathrm{BR}[1]=54,0000$ & $\mathrm{BR}[1]=53,6$ \\
\hline $\mathrm{GS}[1]=63,0000$ & $\mathrm{GS}[1]=61,8$ \\
$\mathrm{BS}[1]=7,0000$ & $\mathrm{BS}[1]=6,9$ \\
\hline
\end{tabular}

\section{4. Çok Özellikli Bağımsız Testin Temel Kavramları}

Çok özellikli test problemi bağımsız test ve etkileşimli test şeklinde iki türden oluşmaktadır. Bağımsız test ürünlerin test edilecek birden fazla özelliğini bağımsız olarak (ayrı ayrı) test etmeyi ve sonuçların bir araya gelerek nihai ürün kalitesinin belirlenmesini öngörür. Testler bağımsız olduğu için herhangi bir özelliğin test işlemi başka bir özelliğin hata durumunu etkilemeyecektir. Örnek bir bağımsız test akışı, Şekil: 2'de verilmiştir. Etkileşimli testte ise bir ürün özelliği, farklı bir özelliğin test ya da tamiri sırasında değişebilir. Bu çalışmada sadece bağımsız test ele alınmaktadır.

Şekilde ürünün test edilecek üç özelliği bulunmaktadır. Bu üç özellik, sırasıyla $\mathrm{T} 1, \mathrm{~T} 2$ ve T3 testlerine girmektedir. Her test diğerinden bağımsız olarak test edilmektedir. Her üç testin sonuçları ise nihai ürünün hata durumunu belirlemektedir. Bu yapı altında çok özellikli testin etkileşim içermeyen üç temel kavramı açıklanacaktır. Bunlardan ilki test kapsamasidır. 
Şekil: 2

Çok Özellikli Bağımsız Test Akışı

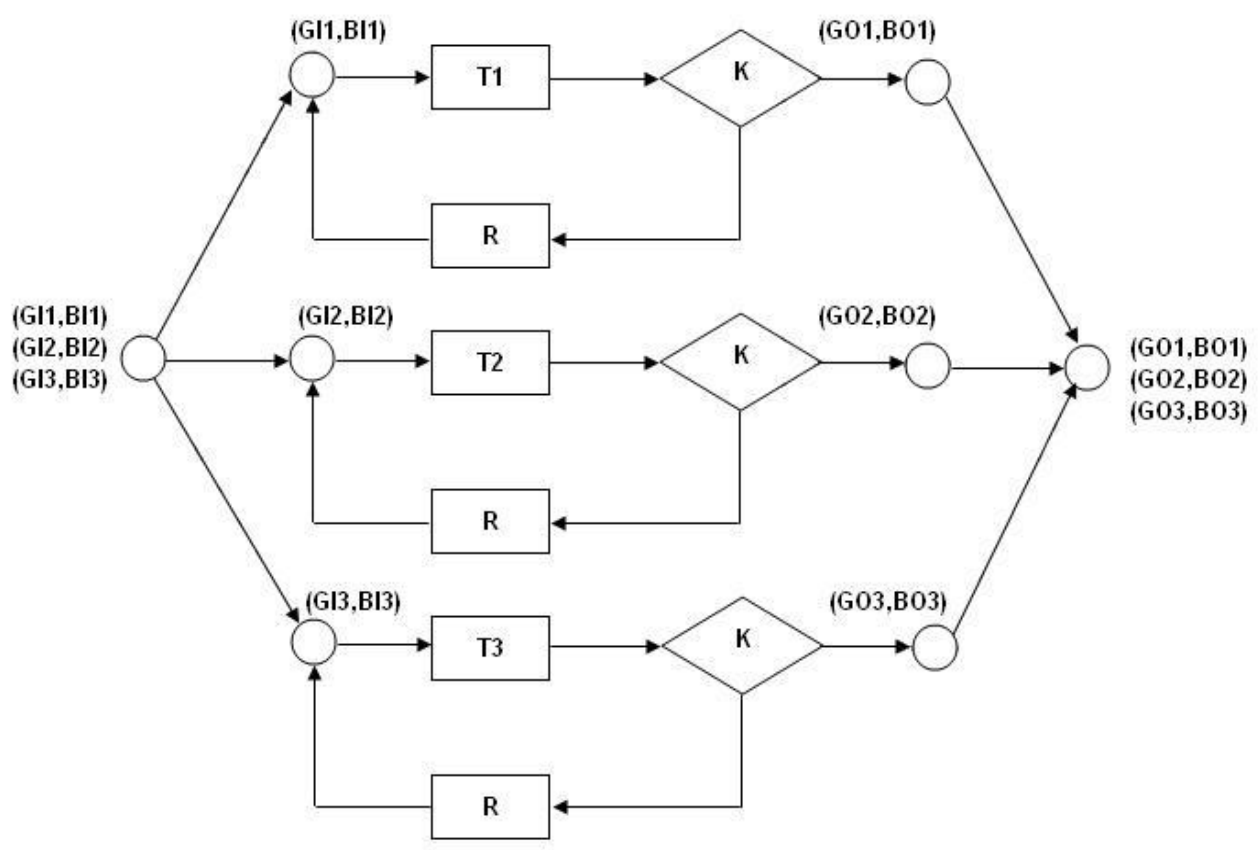

Test kapsamas1, bir ürünün özelliklerinden hangilerinin test edilmesi gerektiği şeklinde açıklanır. Çalışmanın varsayımlarından biri olarak test makinelerinin her türlü fonksiyonel testlerin sadece birini, birden fazlasını, ya da hepsini yapabiliyor olma olasıllığ bulunmaktadır. Örneğin, iki test makinesinden ilki, sadece üçüncü özelliği, diğeri ise hem ilk hem de ikinci özelliği test ediyor ise, her iki makinenin de kullanılması durumunda tüm özellikler test edilmiş olacaktır. Şekil: 2'deki örnekte test kapsaması \%100 olarak tanımlanacak, yani "tam test kapsaması" söz konusu olacaktır. Oysa her makine sadece birer özelliği test ediyor olsa test kapsaması \%66,6 seviyesinde kalacaktır.

İletişim sektöründe kullanılan bir panel kartı üzerinde test edilebilecek yüzlerce özellik bulunmaktadır ve bu özelliklerin her biri aynı düzeyde önemli değildir. Burada kritik olan, test edilecek özellikte rastlanan üretim kalitesi düzeyi ve test edilecek özelliğin nihai üründe aldığ1 rolün önemidir. Firmalar önemsiz ve/veya yüksek yüzdelerle hatasız üretilen parçaları test etmek için zaman harcamayabilir ve bunları test kapsamının dışında tutabilirler. Literatürde de birçok çalışma kaliteden ödün vermeden hata kapsama oranını 
düşürerek maliyetleri azaltma yolunu önermektedirler (Chen ve Lau, 1998 ve Pomeranz ve Reddy, 2003). Böylece test kapsamı için bir alt sınır oluşturulabilir. Bu çalışmada varsayılan temel prensip bağımsız testler için test kapsamasının \%100 olması gerektiğidir.

Bir diğer temel kavram ürün oranıdır. Ürün oranı, hatasız ürün oranını (yield) yani tüm testleri geçen nihai ürünlerin içindeki hatasız nihai ürün oranını göstermektedir. Tanım gereği $\mathrm{y}_{\mathrm{i}}$, tek bir testin sonucunda oluşan hatasız ürün oranı iken, $\mathrm{y}_{\mathrm{t}}$, farklı $\mathrm{y}_{\mathrm{i}}$ değerlerinden oluşan nihai ürün oranı olarak tanımlanır. Çünkü açıkça görülebilir ki nihai ürünün hata yapma olasılığı, içindeki herhangi bir bileşenin hata yapma olasıllğına bağlıdır. Bu durumda ürünün çalışma olasılı̆̆ı, her bir bileşeninin çalışıyor olmasına dayanmaktadır. Böylece çok özellikli test için hatasız nihai ürün oranı şu şekilde yazılabilir:

$$
y_{t}=\prod_{i} y_{i}, \forall i \in[1 . . t]
$$

(29) gereği, çok özellikli testte nihai ürünün başarım oranını belirli bir düzeyin yukarısında tutmak için izlenebilecek iki yol bulunmaktadır. Bunlardan ilki (29)'u modelin içine yerleştirmek ve $y_{t}$ değerine bir kısıt eklemektir. Örneğin, $y_{t}>0,95$ denklemi, nihai ürün başarım oranını \%95'in üzerinde olmaya zorlayacaktır. Diğer yol ise, yt'nin alması istenen değere göre, her bir $y_{i}$ bileşeni için ayrı kısıtlar oluşturmaktır. Örneğin, eşit ağırlıklı üç özellikli bir ürün için, örneğin, her özellik için $\mathrm{y}_{\mathrm{i}} \geq 0,98$ gibi bir kısıt eklenirse, elde edilecek hatasız çıktı oranının olası en düşük değeri aşağıdaki gibi olacaktır:

$$
y_{t}=\prod_{i} y_{i}=0.98 * 0.98 * 0.98=\% 94.12
$$

Son olarak durum vektörü, herhangi bir ürünün test döngüsü içindeki herhangi bir andaki durumunu tanımlamaktadır. Fisher ve diğerleri (2007a), durum vektörü konusunda ayrıntılı tanımlar vermektedirler. Basit bir ifadeyle, beş özelliğe sahip ve ikinci ve dördüncü özelliği hatalı olan bir ürünün üçüncü test döngüsündeki durum vektörü $\mathrm{G}_{3}=$ [ $1,0,1,0,1]$ şeklinde değer alacaktır. Her özellik iki değer (1- hatasız, 0- hatal1) alabileceğinden, $\mathrm{k}$ özellikli bir ürünün herhangi bir zamandaki durum vektörü, $\mathrm{m}=2^{\mathrm{k}}$ alternatif değer alabilecektir (Rossi ve diğerleri, 2006 ve Fisher ve diğerleri, 2007a). Önemli olan, test akışı esnasında herhangi bir anda herhangi bir durum vektörüne sahip kaç ürün olacă̆ıdır. 


\section{5. Çok Özellikli Bağımsız Test için Makine Optimizasyonu}

Oluşturulacak kısıt programlama modeli her bir tek özellik testi için çoğaltılacak ve gerekli yeni kısıtlar eklenerek çok özellikli bağımsız test problemine çözüm aranacaktır. Yeni model bazı ek kısıtlar içerecektir. Bu problemin ürün girdi kitlesi, iyi ve kötü ürün sayısını gösteren bir vektör değil, özellik sayısı ile ilintili bir matris olacaktır. Başka bir deyişle hem iyi hem kötü ürünler ayrı birer vektör olacaktır. Makine sayısı ve ürün oranı kısıtları hariç tüm kısıtlar her test için çoğaltılacak ve bu testlerin çıktıları ürün oranının birleşik olasılık formülü ile birbirlerine bağlanacaktır. Alternatif yol olarak da birleşik olasılık yerine her bir testin çıktısı ayrı olarak belirli bir düzeyin üstünde olmaya zorlanacaktır.

Probleme her makine için, gerçekleştirebileceği tüm testlere dair performans bilgileri ( $\alpha$ ve $\beta$ değerleri) girilecek, makine herhangi bir özelliğin testini yapamıyorsa $o$ testteki performansı ile ilgili test kapsaması durumu dikkate alınacak ve yeni kısıtlar eklenecektir. Öncelikle bir örnek üzerinden iki özellikli bir ürünün seri testi incelenecektir. Mevcut örnekte iki alternatif test makinesi her iki özelliği de test edebilecek niteliklere sahiptir. Problemin girdilerinin yapısı Tablo: 2'de verilmiştir. İndekslerde gözlenen son rakamlar, değerin iki özellik testinden hangisi için geçerli olduğunu göstermektedir. Her iki özellik için de girdilerin yarısı hatasızdır.

Tablo: 2

Çok Değişkenli Bağımsız Test Modeli Girdileri

\begin{tabular}{|c|c|c|}
\hline $\begin{array}{c}\text { Hatasiz Kabul } \\
\text { Olasil } \breve{g}_{1} \\
\alpha_{\mathrm{tp}, \mathrm{t} 1,1}=0,75 \\
\alpha_{\mathrm{tp}, \mathrm{t} 2,1}=0,90 \\
\alpha_{\mathrm{tp}, \mathrm{t} 1,2}=0,85 \\
\alpha_{\mathrm{tp}, \mathrm{t} 2,2}=0,90\end{array}$ & $\begin{array}{c}\text { Hatasiz Ret } \\
\text { Olasilığ } 1 \\
\alpha_{\mathrm{tf}, \mathrm{t} 1,1}=0,75 \\
\alpha_{\mathrm{tf}, \mathrm{t} 2,1}=0,90 \\
\alpha_{\mathrm{tf}, \mathrm{t} 1,2}=0,95 \\
\alpha_{\mathrm{tf}, t 2,2}=0,90\end{array}$ & $\begin{array}{l}\text { Sabit Maliyetler } \\
\mathrm{Fc}_{\mathrm{t} 1}=200000 \\
\mathrm{Fc}_{\mathrm{t} 2}=100000\end{array}$ \\
\hline $\begin{array}{l}\text { Hatalı Ret Olasılı } \breve{g}_{1} \\
\qquad \begin{aligned} \alpha_{\mathrm{ff}, \mathrm{t} 1,1} & =0,25 \\
\alpha_{\mathrm{ff}, \mathrm{t}, 1} & =0,10 \\
\alpha_{\mathrm{ff}, \mathrm{t} 1,2} & =0,15 \\
\alpha_{\mathrm{ff}, \mathrm{t}, 2} & =0,10\end{aligned}\end{array}$ & $\begin{array}{c}\text { Tamir Parametreleri } \\
\begin{aligned} \beta_{\mathrm{bb}} & =0,2 \\
\beta_{\mathrm{bg}} & =0,8 \\
\beta_{\mathrm{gb}} & =0,2 \\
\beta_{\mathrm{gg}} & =0,8\end{aligned}\end{array}$ & $\begin{array}{l}\text { Test Kapasiteleri } \\
\qquad \begin{aligned} \text { Cap }_{\mathrm{t} 11} & =50 \\
\text { Cap }_{\mathrm{t} 21} & =50 \\
\text { Cap }_{\mathrm{t} 12} & =50 \\
\text { Capa }_{\mathrm{t} 22} & =50\end{aligned}\end{array}$ \\
\hline $\begin{array}{l}\text { Hatalı Kabul Olasilığ } 1 \\
\begin{aligned} \alpha_{\mathrm{fp}, \mathrm{t} 1,1} & =0,25 \\
\alpha_{\mathrm{fp}, \mathrm{t} 2,1} & =0,10 \\
\alpha_{\mathrm{fp}, \mathrm{t} 1,2} & =0,05 \\
\alpha_{\mathrm{fp}, \mathrm{t} 2,2} & =0,10\end{aligned}\end{array}$ & $\begin{array}{c}\text { Değişken Maliyetler } \\
\mathrm{Vc}_{\mathrm{t} 1,1}=200 \\
\mathrm{Vc}_{\mathrm{t} 2,1}=100 \\
\mathrm{Vc}_{\mathrm{s}, 1}=300 \\
\mathrm{~V}_{\mathrm{t} 1,2}=100 \\
\mathrm{Vc}_{\mathrm{t} 2,2}=100 \\
\mathrm{Vc}_{\mathrm{s}, 2}=100\end{array}$ & $\begin{array}{l}\text { Kaçış maliyeti, Ürün Oranı ve En Fazla Makine } \\
\text { Sayıs1 } \\
\qquad \begin{array}{c}\mathrm{Fc}=100 \\
\mathrm{y}=0,80 \\
\mathrm{~nm}=50\end{array}\end{array}$ \\
\hline
\end{tabular}


Problemin modellenmesinde ise önceki kısımda verilen ve her test için indekslenerek çoğaltılan kısıtlara ek olarak sadece çıktı ile ilgili kısıtlar eklenmiştir. Bu kısıtlar hem birleşik olasılık ile ürün oranını hesaplamakta, hem de oranı önceden belirlenmiş bir değerin (bu problem için örneğin, $y=0,80$ ) üstünde olmaya zorlamaktadır. Eklenecek kisitlar:

$$
\begin{aligned}
& \mathrm{GO}=\prod_{\mathrm{i}} G I_{1^{*} i} \\
& \frac{G O}{10000} \geq y
\end{aligned}
$$

(27), her bir özelliğin test süreci sonundaki hatasız ürün olasıllklarının çarpımını, yani nihai ürünün hatasız olma olasılığını vermektedir. (28) ise bu oranı belirli bir kalite parametresinin üzerinde olmaya zorlamaktadır. Yukarıda verilen problem çözüldüğünde bulunan çözüm aşağıdaki gibidir:

Tablo: 3

\section{Çok Aşamalı Çözüm}

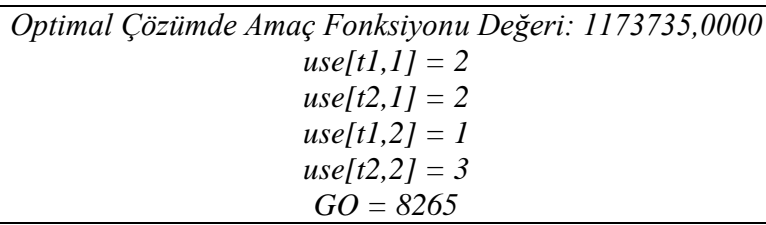

Çözüm, ilk testte her iki makineden ikişer tane, ikinci testte ise ilk makineden bir, ikinci makineden üç tane kullanıldığını göstermektedir. Çıktı oranı $\% 82,65$ 'te kalmıştır. Çözücü, ilk etapta 1474735 birimlik toplam maliyete sahip bir uygun çözüm bulmuş ve ancak altıncı aşamada en iyi sonucu elde edebilmiştir. En iyi çözüme ulaşıldığında 1173735 birimlik toplam maliyet oluşmuştur. Bu maliyet tek özellikli test probleminin kısıt programlama ile çözüldüğünde bulunan 427000 birimlik maliyetin 2,5 katından biraz fazladır. Yapılan denemelerde görülmüştür ki mevcut makineler ve ürün özellikleri ile ürün kalitesinin \%89'a kadar çıkarılma olanağı bulunmaktadır. Böyle bir durumda çözüm aşağıdaki gibidir: 


\title{
Tablo: 4
}

\section{Kısıtlı Çözüm}

\author{
Optimal Çözümde Amaç Fonksiyonu Değeri: 1479072,0000 \\ use $1[t 1,1]=2$ \\ use $1[t 2,1]=2$ \\ use $2[t 1,1]=3$ \\ use $2[t 2,1]=2$ \\ $G O=8928$
}

Modele çıktı oranı üzerinden kısıtlama yapıldığı takdirde, ürün oranının \%89,28'e kadar artırılabildiği görülmektedir. Böyle bir durumda bir önceki çözümden farklı olarak toplamda 8 yerine 9 makine kullanılmıştır. Seçilen makine düzeni ilk test için aynı kalırken, ikinci testte ciddi farklılıklar göstermektedir. Bu modelde toplam test performansı için kritik olan teste tabi özellik ikinci testtir. Elde edilen yaklaşık \%6,63'lük kalite artırımı, maliyet cinsinden yaklaşık \%26'lık bir ek masraf ile karşılanabilmektedir. Bir diğer önemli nokta, bu çıktı oranı, mevcut makinelerin herhangi birleşimi ile elde edilebilecek en iyi orandır. Başka bir deyişle $\mathrm{y}=0,90$ gibi bir değer kısıt olarak belirlendiği takdirde, çözücü sadece en iyi çözüme değil, herhangi bir uygulanabilir çözüme ulaşamamaktadır.

Genel bir kural olarak girdilerdeki iyileştirmeler ya amaç fonksiyonuna maliyet tasarrufu olarak yansımalı ya da artırılması tercih edilecek değişkenler üzerinde olumlu etkilerde bulunmalıdır. Beklenen ise hatasız çıktı oranının artmasıdır. Bir önceki problemin girdilerinde sadece $\mathrm{T}_{1}$ test makinesinin ilk test için bozuk ürünlerde gösterdiği performansını sadece $\% 10$ değiştirilecektir. Böylece $\alpha_{\mathrm{tf}, \mathrm{t} t, 1}$ parametresi 0,75 yerine 0,85 , ve $\alpha_{\mathrm{fp}, t 1,1}$ parametresi 0,25 yerine 0,15 olacaktır. Yeni sonuçlar Tablo: 5'te gösterilmiştir.

Tablo: 5

\section{Modifiye Çözüm}

Optimal Çözümde Amaç Fonksiyonu Değeri: 1263872.0000

$$
\begin{gathered}
\text { use } 1[t 1,1]=1 \\
\text { use } 1[t 2,1]=3 \\
\text { use } 2[t 1,1]=3 \\
\text { use } 2[t 2,1]=1 \\
G O=8928
\end{gathered}
$$

Modelin çözümünde çıktı oranı değişmemiştir. Fakat makine seçimlerinde radikal bir değişiklik ortaya çıkmış ve farklı makine seçimi ile maliyetler yaklaşık \%14.6 oranında azaltılmıştır. Bu problemin önemli noktaları Şekil: 3 'te verilmiş̧ir. 
Çözümlerde dikkat çeken, tam sayılaştırılmış kısıtlar yerine hafif akış orantılama kısıtları kullanılmasına rağmen dört test makinesi tipinde de çok yakın hatasız ürün oranı dağılımı görülmesidir. Bu değerler sırasılyla \%63.15, \%61.42, \%64.62 ve $\% 51.43$ olarak hesaplanmaktadır. Son makinede görülen yaklaşık $\% 10$ fark ise modelin makine verimliliğini de dikkate almasından kaynaklanmakta ve son makinenin sadece diğer test makinelerinden geriye kalan ürünleri test ediyor olmasına dayanmaktadır. $\mathrm{Bu}$ şartlar test tasarımının rastsal bir yapıda test sürecini hesapladığını göstermektedir.

\section{Sekil: 3}

\section{İki Özellikli Seri Test-Grafik Çözüm}

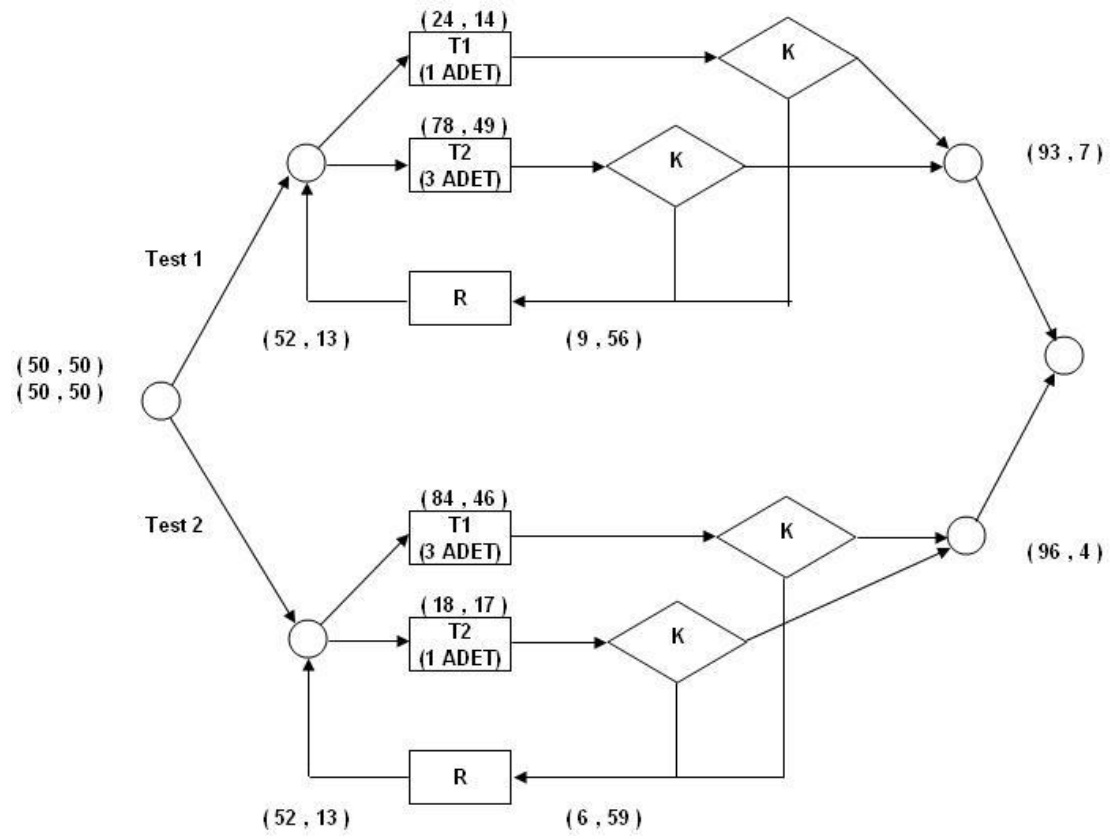

$(89.28,10.72)$

Çözümü hızlandırmak amacıyla ise yaygın kullanılan bir yöntem olarak kesmeler kullanılmıştır. $\mathrm{Bu}$ amaçla modelin öncelikle amaç fonksiyonu $\mathrm{Z}$ değişkenine eşitlenmiş, daha sonra $Z$ değeri model içinde amaç fonksiyonuna atanmış (33) ve bulunan amaç fonksiyonu değeri (A) kesme olacak şekilde kısıt olarak eklenmiş̧ir (34). 
$Z=\sum_{t}\left(V c R^{*}(G S[1, t]+B S[1, t])+F c^{*} B I[1]+\sum_{i} V c T_{i, t} *\left(G T_{i}[1, t]+B T_{i}[1, t]\right)+\sum_{i} F c T_{i}^{*} u s e\left[t_{i}, 1, t\right]\right)$

$\mathrm{Z} \leq \mathrm{A}$

Son model bütünlük bozulmadan ve aynı prensipler uygulanarak tamir makinesinin seçimi için de genellenebilecektir. Özellik sayısı, alternatif makine sayısı değiştirilerek çözümü istenen probleme uyarlanabilecektir. Çözümün genişletilmiş problemlerde de oldukça hızlı elde edildiği yapılan uygulamalarda gözlenmiştir. Fakat etkileşimli test durumunun söz konusu olduğu durumlarda, bu çalışmada önerilen yapı da yetersiz kalmakta ve tamamen farklı bir hesaplama ve modelleme yaklaşımı gereği doğmaktadır. Oluşan problem oldukça zor ve karmaşıktır ve bu çalışmanın kapsamı altında tutulmamıştır.

\section{Sonuç}

Bu çalışmada basit bir test - tamir döngüsü altında çok özellikli bir ürünün testinde kullanılan, performans hesapları ve makine optimizasyonu için geliştirilen bir kısıt programlama modeli sunulmuştur. Bu problem, tek özellikli test için geçerli olacak bir modelin çok sayıda özellik ve çok sayıda alternatif makineyi kapsayacak şekilde genişletilmesi ve nihai üründe istenen hatasızlık oranını zorlayacak şekilde yeni kısıtlarla desteklenmesi ile çözülebilir. Kısıt programlama modeli gerçekçi stratejiler önermekte ve doğru maliyetleri ortaya koymaktadır. Model ayrıca test makinesi seçimi üzerinden test kapsama problemine de bir çözüm getirmekte ve bunu en ekonomik yoldan yapabilmeyi sağlamaktadır.

\section{Kaynakça}

Chen, T.Y. \& M.F. Lau (1998), “A New Heuristic for the Test Suite Reduction”, Information and Software Technology, 40, 347-354.

Dick, J.H. \& E. Trischler \& C. Dislis \& A.P. Ambler (1994), "Sensitivity Analysis in Economic Based Test Strategy Planning", Journal of Electronic Testing: Theory and Applications (JETTA), 5, 239-252.

Dislis, C. \& I.D. Dear \& S.C. Lau \& J.R. Miles \& A.P. Ambler (1988), "Hierarchical Test Strategy Planning Based on Cost Evaluation", IEE Colloquium on Computer Aided Test and Diagnosis, 7/1-7/8.

Fisher, E. \& S. Fortune \& M. Gladstein \& S. Goyal \& W.B. Lyons \& J. Mosher \& G. Wilfong (2007a), "Economic Modeling of Global Test Strategy I: Mathematical Models", Bell Labs Technical Journal, 12 (1), 161-173. 
Fisher, E. \& S. Fortune \& M. Gladstein \& S. Goyal \& W.B. Lyons \& J. Mosher \& G. Wilfong (2007b), "Economic Modeling of Global Test Strategy II: Software System and Examples", Bell Labs Technical Journal, 12 (1), 175-186.

Flehinger, B.J. (1965), "Product Test Planning for Repairable Systems”, Technometrics, 7 (4), $485-$ 494.

Gluss, B. (1959), “An Optimum Policy for Detecting a Fault in a Complex System”, Operations Research, 7 (4), 468-477.

Goyal, S. \& J.H. Mosher (2006), “An Improved Test Process Model for Cost Reduction”, Bell Labs Technical Journal, 11 (1), 173-190.

Nachlas, J.A. \& S.R. Loney \& B.A. Binney (1990), "Diagnostic-Strategy Selection for Series Systems", IEEE Transactions on Reliability, 39 (3), 273-280.

Pomeranz, I. \& S.M. Reddy (2003), "On Maximizing the Fault Coverage for a Given Test Length Limit in a Synchronous Sequential Circuit", Proceedings of the 21 st IEEE VLSI Test Symposium (VTS' 03).

Rossi, R. \& S.A. Tarım \& B. Hnich \& S. Prestwich (2006), "Multi-Component Testing in Telecommunications", Proceedings of the European Conference on Operational Research EURO XXI.

Volkerink, E.H. \& A. Khoche \& L.A. Kamas \& J. Rivoir \& H.G. Kerkhoff (2001), "Tackling Test Trade-Offs from Design, Manufacturing to Market Using Economic Modeling", Proceedings of the IEEE International Test Conference, 1098-1107.

Wilson, S. \& B. Flood \& S. Goyal \& J. Mosher \& S. Bergin \& J. O’Brien \& R. Kennedy (2007), "Parameter Estimation for a Model With Both Imperfect Test and Repair", Proceedings of 25th IEEE VLSI Symposium (VTS'07).

Wilson, S. \& S. Goyal (2012), "Estimating Production Test Properties from Test Measurement Data", Applied Stochastic Models in Business and Industry, 28, 542-557. 
Onur KOYUNCU

228 